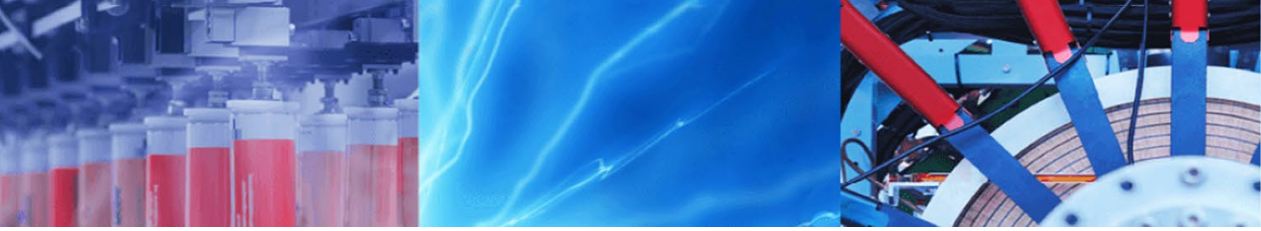

Research Article

\title{
Mechanical and thermal behavior of epoxy based halloysite nano clay/ PMMA hybrid nanocomposites
}

\author{
M. Rudresh ${ }^{1}$ (D) B. H. Maruthi ${ }^{1} \cdot$ K. Channakeshavalu ${ }^{1}$ H. P. Nagaswarupa ${ }^{2}$
}

(c) Springer Nature Switzerland AG 2019

\begin{abstract}
In the present study, the influence of Modified Halloysite Nanoclay Tubes (MHNT's) and Poly-Methyl-Metacrylate (PMMA) on the mechanical and thermal properties of Epoxy/PMMA/MHNT hybrid nanocomposites have been investigated. Different wt $\%$ of MHNT's was dispersed in epoxy resin and then added to dissolved-PMMA to obtain three phase hybrid nanocomposites. The composites were characterized by using X-Ray Diffraction (XRD), Scanning Electron Microscopy (SEM), Fourier Transform-Infrared Spectrometry (FT-IR), Thermo-gravimetric analysis, tensile test, three point bending test and fracture toughness test. SEM images revealed that PMMA forms an immiscible phase in epoxy matrix. XRD patterns revealed that MHNT's were in fully exfoliated state in hybrid nanocomposites. The MHNT's provides good ductility to Epoxy-PMMA blends by forming flexible interface, results in significant improvement in the elongation at break and hence tensile strength. The values of tensile modulus, flexural strength, flexural modulus, fracture toughness and thermal stability showed significant improvement compared to neat epoxy. Hybrid composites exhibited better properties than conventional resin blend and nanocomposites due to positive divergence generated from the combination of two dissimilar toughening mechanisms.
\end{abstract}

Keywords Hybrid nanocomposites · Epoxy PMMA · Halloysite nano clay

\section{Introduction}

Epoxy thermosetting polymers are extensively used as matrix phase in high performance applications in aerospace and automobile industries. Epoxy resins are inherently brittle and poor resistance to crack growth due to high cross-linking density results in limiting their usage as structural materials. The mechanical properties of epoxy matrices has been improved by adding nano materials and polymeric fillers like thermoplastics, rubber particles, carbon nanotubes, nano silica, nanoclay and grapheme [1-6]. Zhang et al. [7] observed 30 to $40 \%$ enhancement in tensile strength and flexural modulus by adding silica as reinforcement in epoxy resin. Bakar et al. [8] investigated the effect of reactive polyster and kaolin on the mechanical properties of epoxy resin. They showed that significant enhancement in impact and flexural strength due to addition of kaolin clay and polyster in epoxy. Abhishek K. Pathaka et al. [9] investigated the mechanical properties of hybrid composites by adding carbon fibre/grapheme oxide into brittle epoxy resin. They observed that, flexural strength amplified by $66 \%$, flexural modulus by $72 \%$, while interlaminar shear strength improved by $25 \%$ in polymer hybrid composites.

Previous studies carried out on PMMA and epoxy resin systems have concerned mainly their reaction kinetics and miscibility. The miscibility, curing, dynamic properties, and morphology of composites based on PMMA and epoxy was studied by Cook et al. [10]. It was seen that the inclusion of PMMA caused a slight decrease in curing rate because of dilution effect. Moreover, evidence of phase separation of the components into PMMA loaded domain

M. Rudresh, rudreshm@ewit.edu | 'Department of Mechanical Engineering, East West Institute of Technology, Bengaluru 560091, India. ${ }^{2}$ Research Center, Department of Chemistry, East West Institute of Technology, Bengaluru 560091, India.

SN Applied Sciences (2019) 1:687 | https://doi.org/10.1007/s42452-019-0749-0 
and an epoxy-rich matrix was provided by dynamic mechanical thermal analysis and confirmed with electron microscopy studies. And also, the unification of little measures of PMMA with the epoxy resin appeared to source just a modest sacrifice in thermal resistance.

The halloysite nanoclay was found over 100 years prior, however was used for applications just in the last 10-20 years when it accessible in unadulterated structure. Almost every natural kaolin deposit has a fraction of halloysite, which is often referred to as rolled kaolin, but there are only a few deposits where halloysite is presented in almost pure form and contains $90-95 \mathrm{wt} \%$ of tubular structure. HNT has the advantage of using existing processing techniques, similar to other clays, however it has a special extended rod-like shape with axis ratio of 20:1 and an inner lumen which may contain distinctive functional chemicals for sustained release. Besides, HNT dispersion to single particles is much simpler because these clay nanotubes are not stacked together as platy kaolin, montmorillonite, or bentonite particles [11]. The high aspect ratio of HNTs helps reinforce polymers in composites by optimising the load transfer from the matrix to the nanotubes [12].

In our previous research work, we investigated the effect of PMMA on mechanical properties of epoxy [13] and effect of MHNT on mechanical and thermal properties of epoxy alone [14]. But the research in addition of MHNT's in the thermoplastic toughened epoxy is not dealt. More ever, mechanical properties were also not evaluated on above mentioned hybrid nanocomposites. The fundamental reason for this study is to estimate the influence of PMMA as thermoplastic phase and MHNT's as nano reinforcement on mechanical and thermal properties of hybrid nanocomposites.

\section{Experimental details}

\subsection{Materials used}

For fabrication of epoxy based hybrid nanocomposites, Halloysite nanoclay (kaolin clay) (HNT's) and Poly-methyle-metacrylate (PMMA) was used as reinforcement. HNT's with average diameter 30-70 $\mathrm{nm}$, length 1-3 $\mu \mathrm{m}$ and (3-Aminopropyl)trimethoxysilane as modifier for HNT supplied from Sigma Aldrich, India. Epoxy resin (LAPOX L-12) Bisphenol-A-Diglycidyl-Ether (DGEBA) with an epoxide equivalent weight of $185 \mathrm{~g} / \mathrm{eq}$ formed the foundation of all the materials examined in the present work. Hardner diamino-diphenyl-methane (DDM) with commercial designation $\mathrm{K}-6$ is selected for the present work. The LAPOX $\mathrm{L}-12$ epoxy resin and the corresponding curing agent K6 are of commercial grade are supplied from Atul Ltd. Gujarat, India. PMMA of commercial grade in the form of granules with glass transition temperature of $105^{\circ} \mathrm{C}$ was purchased from chemical house of Bangalore, India. Acetone $(\mathrm{CH} 3) 2 \mathrm{CO}$, used as PMMA solvent, was purchased from Nice Chemicals $(P)$ Ltd. Kerala, India.

\subsection{Preparation of hybrid nanocomposites}

Modification of Halloysite nano clay has been done to reduce agglomeration, using 3-aminopropyltriethoxysilane in the presence of distilled water as solvent media. Hybrid nanocomposites were prepared with addition of MHNT's at varying amounts (1, 2, 3 and $4 \mathrm{wt} \%)$ and fixed amount of $6 \mathrm{wt} \%$ of dissolved-PMMA to epoxy resin matrix, $6 \mathrm{wt} \%$ of PMMA is selected because at this wt\% superior mechanical properties were observed. Epoxy resin and MHNT's were blended by mechanical stirring for $0.5 \mathrm{~h}$ followed by ultra-sonication for $0.5 \mathrm{~h}$ at $50{ }^{\circ} \mathrm{C}$ [15]. The dissolved-PMMA was then added to each blend and then stirred for $20 \mathrm{~min}$ at $60^{\circ} \mathrm{C}$ to remove solvent. The blend is cooled to room temperature and hardener was then added and stirred for $5 \mathrm{~min}$. The blend was poured immediately into the molds prepared according to ASTM standards. The molds were kept in autoclave for curing at $85^{\circ} \mathrm{C}$ for $8 \mathrm{~h}$. Flow chart of preparation of samples is shown in Fig. 1.

\subsection{Characterization of epoxy hybrid nanocomposites}

XRD analyses were performed by using Philips X'pert-PRO $\mathrm{X}$-ray diffractometer with graphite monochromatized $\mathrm{CuK}_{\mathrm{a}}$ anode $\left(\lambda=1.5418 \AA\right.$ ) radiation at the scan rate of $2^{\circ} \mathrm{min}^{-1}$ and $2 \theta$ ranging from $10^{\circ}$ to $80^{\circ}$. SEM analysis was carried out on fractured surfaces of the samples using field emission scanning electron microscopy (VEGA3 TESCAN) and all samples were coated with a thin layer of sputtered gold before analysis. Fourier Transform Infrared Spectrophotometer (FT-IR) of SHIMADZU (Model: IRAffinity-1S) is used to take FT-IR spectra in the range from 400 to $4000 \mathrm{~cm}^{-1}$ in transmission measurement mode. The instrument resolution is set for $4 \mathrm{~cm}^{-1}$ and with 45 numbers of scans. TGA was done on 15-16 mg samples on a Perkin Elmer Simultaneous Thermal Analyzer (STA) 8000 instrument with alumina sample pan in a $20 \mathrm{ml} / \mathrm{min}$ nitrogen flow, heating from 50 to $800^{\circ} \mathrm{C}$ with a heating rate $20^{\circ} \mathrm{C} / \mathrm{min}$.

\subsection{Mechanical properties}

Tensile test were conducted as per ASTM D638 standards (specimen dimension $50 \mathrm{~mm}$ long, $13 \mathrm{~mm}$ width and $5 \mathrm{~mm}$ thickness) at a constant rate of traverse of the moving grip of $1 \mathrm{~mm} / \mathrm{min}$. Three point bending test specimens are tested according to ASTM D790 (standard 


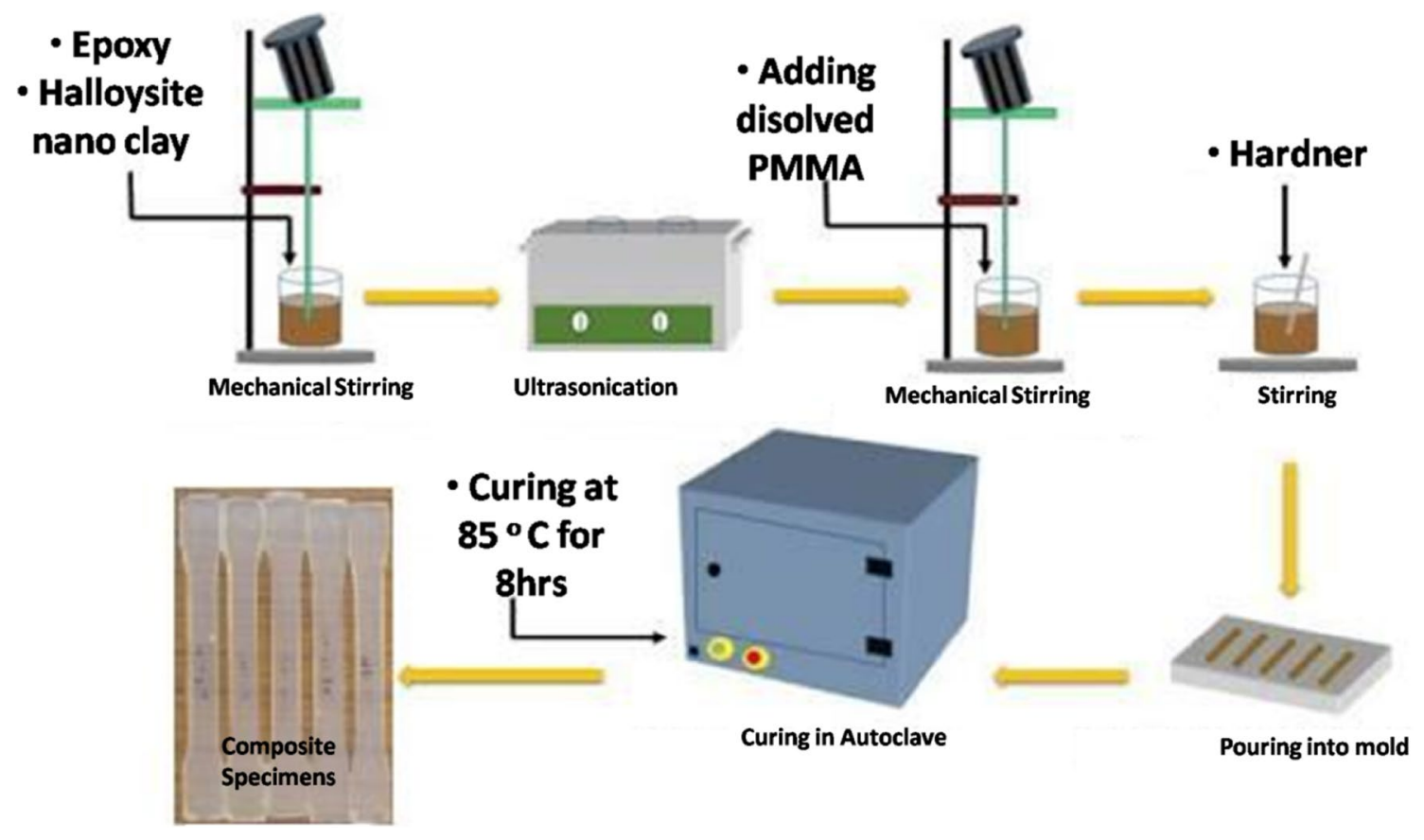

Fig. 1 Flow chart for preparation of hybrid nanocomposites

dimension of $125 \mathrm{~mm} \times 12.7 \mathrm{~mm} \times 3.2 \mathrm{~mm}$ ) at a constant rate of traverse of the moving grip of $5.2 \mathrm{~mm} / \mathrm{min}$ and support span of $100 \mathrm{~mm}$. Fracture toughness specimens are tested according to ASTM E399 (standard dimension of $48 \mathrm{~mm}$ long, $10 \mathrm{~mm}$ width and $5 \mathrm{~mm}$ thickness) at a rated speed of $2 \mathrm{~mm} / \mathrm{min}$, with distance between supports is $40 \mathrm{~mm}$. Five specimens of each composition are tested using a UTM AUTOGRAPH AG-IS $10 \mathrm{KN}$.

\section{Results and discussion}

\subsection{FT-IR of epoxy hybrid nanocomposites}

Figure 2 shows FT-IR spectrum of neat epoxy, the peaks at 913 and $761 \mathrm{~cm}^{-1}$ in the FTIR spectra were allocated to the characteristic absorptions of epoxy group and peaks with wavelength $3700 \mathrm{~cm}^{-1}$ are characterized for hydroxyl groups of epoxy resin or secondary amines [16]. From Fig. 3 it can be seen that as amount of MHNT's was increased, the height of the epoxy hydroxyl groups decreased $\left(3700 \mathrm{~cm}^{-1}\right)$, while peaks related to epoxy groups remain unchanged at 913 and $761 \mathrm{~cm}^{-1}[17,18]$. The peaks at $1790 \mathrm{~cm}^{-1}$ depicts the spectrum of PMMA functionalized MHNT's, mainly due to the $\mathrm{C}=\mathrm{O}$ band of $-\mathrm{COOCH}_{3}$ groups [19].

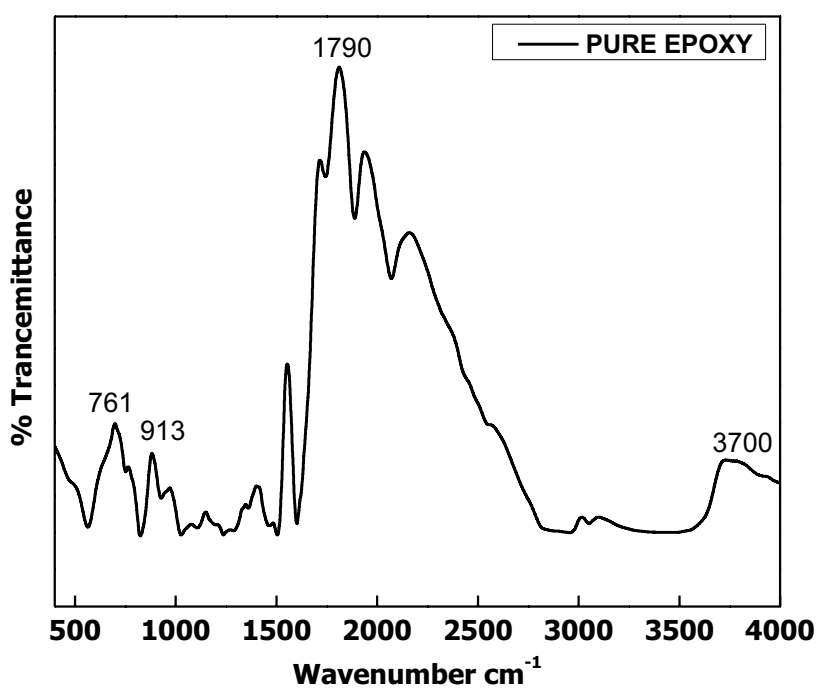

Fig. 2 FT-IR spectra of neat epoxy

\subsection{SEM of hybrid nanocomposites}

The Fig. 4 shows SEM images of fractured surface of tensile samples at most favorable content of MHNT, PMMA and hardener in epoxy. Cross-linking density plays important role in epoxy materials, to attain better mechanical properties. As seen in Fig. 4b, c, fine dispersion of MHNT's and PMMA as thermoplastic phase with little agglomeration is occurred (up to $4 \mathrm{wt} \%$ MHNT). It can also be observed 


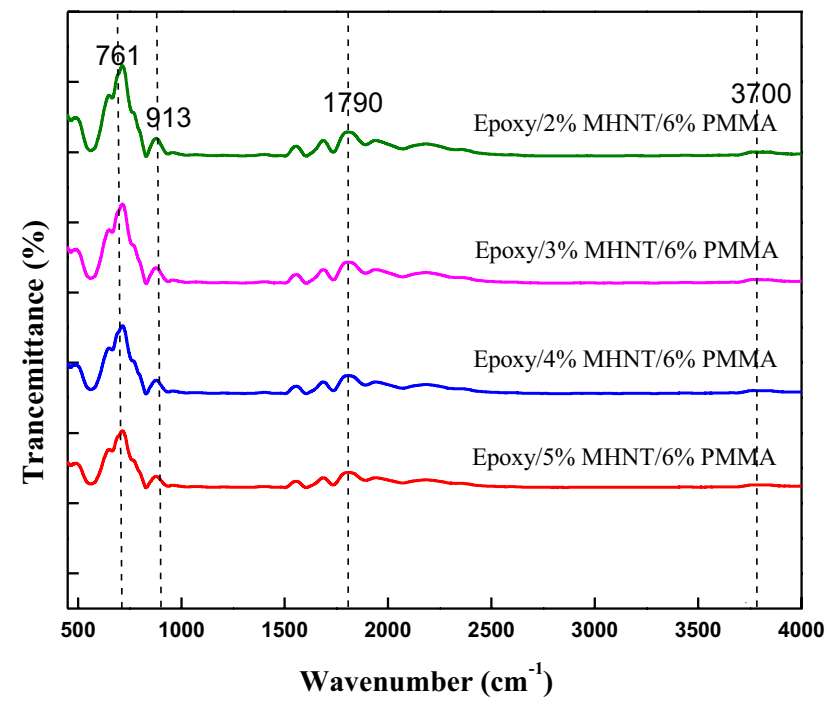

Fig. 3 FT-IR spectra of hybrid nanocomposites

that phase separation of nano and micro particles in epoxy resin matrix [20]. And also, in 2 wt\% MHNT's crack deviation mechanism was less substantial, as shown in Fig. 4b and $\mathrm{c}$. In addition, high energy can be dissipated in epoxy hybrid nanocomposites up to $4 \mathrm{wt} \% \mathrm{MHNT}$, and higher strength can be obtained. More ever, as the crack encountered the modified MHNT's in epoxy matrix, it should pass by either the MHNT or break through it; hence, much more energy would be consumed. As shown in Fig. $4 d$, crack blunting/branching, pull-out mechanism and crack pinning can be observed in fracture surface of epoxy hybrid nanocomposites included with $5 \mathrm{wt} \%$ of MHNT's and 6 wt\% PMMA [21]. As clay content increases, clay particles form larger agglomarates and joins PMMA domains which may act as defect and instigate failure.

\subsection{XRD of hybrid nanocomposites}

So as to distinguish the morphology framed during the hybrid nanocomposites preparation process, XRD spectra were generated, for neat epoxy and hybrid nanocomposites. Figure 5 shows XRD patterns of neat epoxy resin whose peaks show at $2 \theta=20^{\circ}$ indicating the amorphous nature. Therefore the cured epoxy is noncrystalline. Figure 6 shows XRD pattern of Epoxy/MHNT/ PMMA hybrid nanocomposites. It has been found that the XRD pattern of hybrid nanocomposites, diffraction peak is shifted to $2 \theta=18^{\circ}$. The shift of the diffraction
Fig. 4 SEM images of (a) Neat epoxy; b Epoxy/2 wt\% MHNT/6 wt\% PMMA (c) Epoxy/4 wt\% MHNT/6 wt\% PMMA (d) Epoxy $/ 5$ wt $\%$ MHNT/6 wt\% PMMA
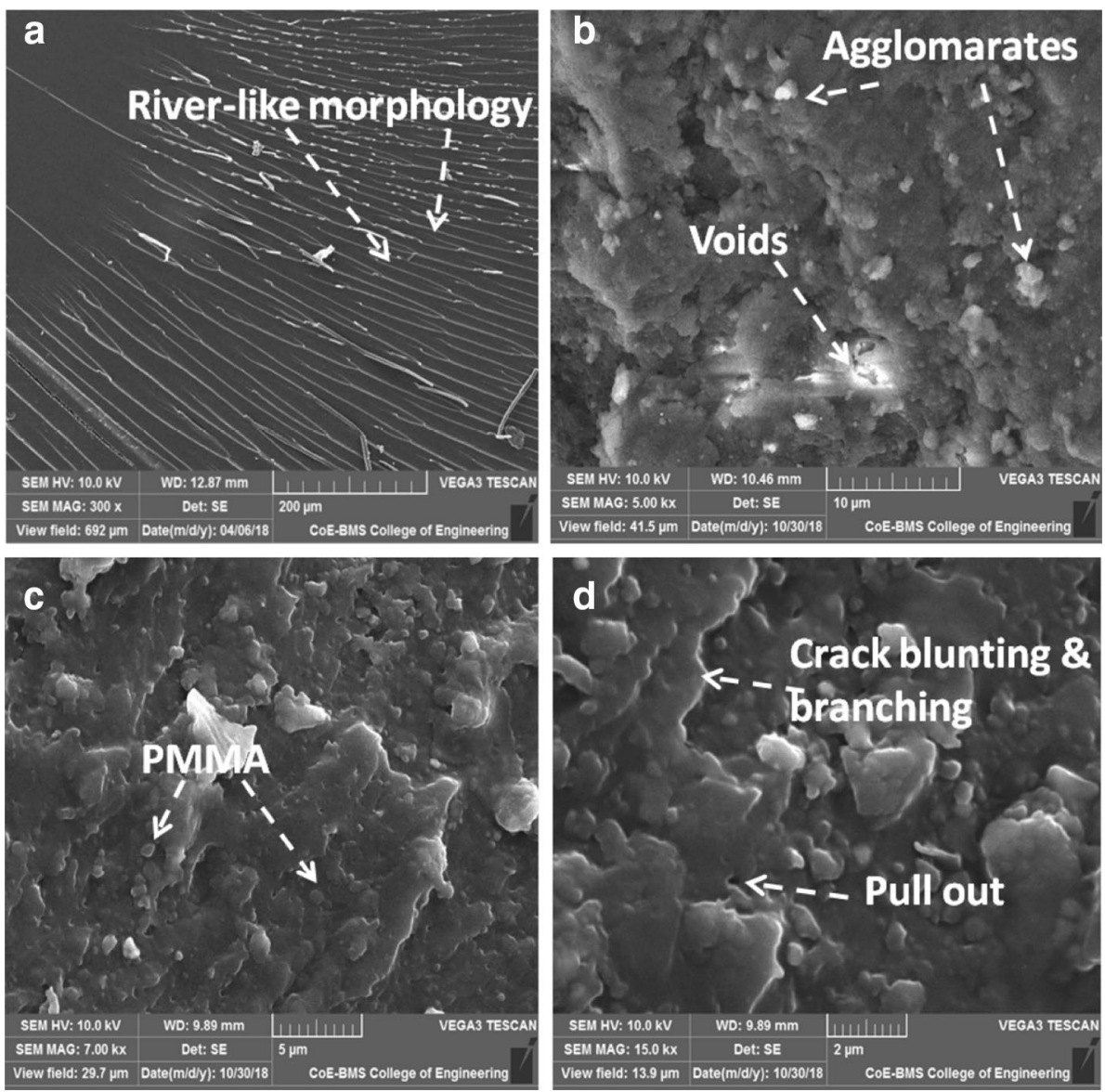


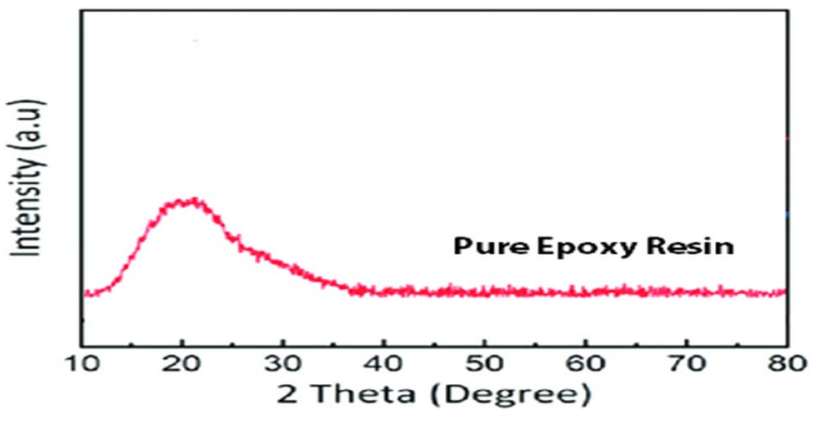

Fig. 5 XRD patterns of pure epoxy resin specimen

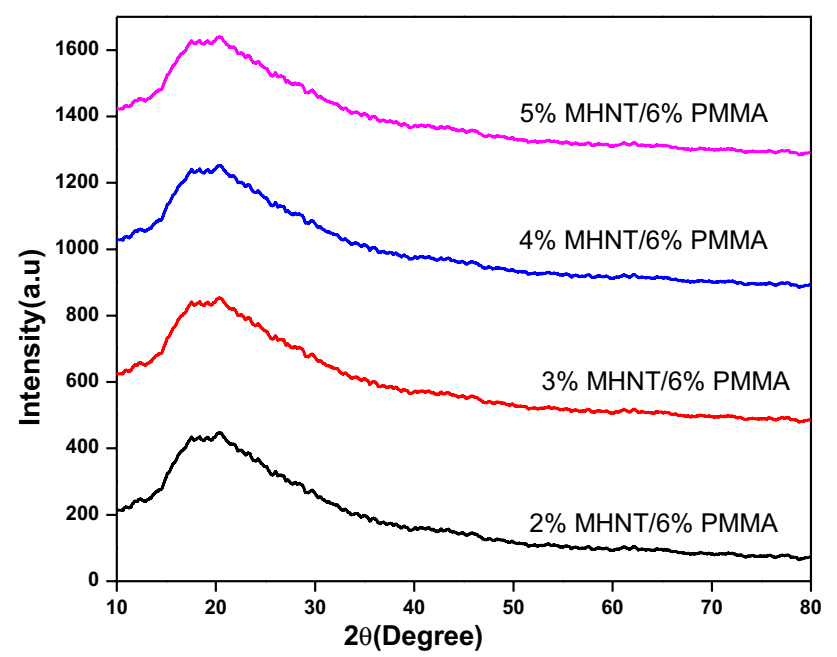

Fig. 6 XRD patterns of hybrid nanocomposites

peaks towards lesser angles indicates that all the prepared nanocomposites are portrayed by an intercalated structure, with an expansion of the interlamellar d-spacing with reverence to the original HNT. The hybrid nanocomposites didn't highlight any peak, regardless of MHNT content, in the XRD range of $2^{\circ}$ to $10^{\circ}$. This means the polymer had the capacity to enter between the MHNT platelets bringing about conceivable exfoliated or tangled intercalated morphology. Nonetheless, with increasing the MHNT content to $5 \mathrm{wt} \%$, a weak scattering peak showed up with a slight substantial d-spacing. The low dispersion at high concentration of clay might be because of agglomeration of clay platelets within hybrid nanocomposites [22].

And also, it can be noted that PMMA domains don't enter into the clay galleries and the interlayer spacing doesn't alter with the inclusion of PMMA. Since PMMA has a much better molecular weight, it is required to diffuse less in between the clay layers [23].

\subsection{Thermal stability of hybrid nanocomposites}

TGA was carried out to study the thermal stability of the hybrid nanocomposites. Thermogravimetric graphs of the hybrid nanocomposites with $6 \mathrm{wt} \%$ PMMA and different amount of MHNT's and epoxy are shown in Fig. 7. Hybrid nanocomposites with $6 \mathrm{wt} \%$ of PMMA and $1-2 \mathrm{wt} \%$ of MHNT demonstrated a more gradual weight reduction than the composites contain higher wt $\%$ MHNT. The reality that the PMMA is more exceptionally cross-linked than the epoxy might be the reason for the more gradual weight reduction of the composites at $350-450{ }^{\circ} \mathrm{C}$. An initial weight reduction of all the composites at low temperature was similar because of evaporation of moisture and un-reacted epoxy resin [24, 25].

The $40 \%$ weight loss for neat epoxy, epoxy/PMMA/ MHNT hybrid nanocomposites were occurred at the temperature of $394,377,388,402$ and $411^{\circ} \mathrm{C}$ correspondingly. Likewise it was seen that the $60 \mathrm{wt} \%$ reduction of the composites occurred at the temperature of 421,404 , 423,477 and $508{ }^{\circ} \mathrm{C}$ respectively. The inclusion of PMMA into the epoxy initially degrades at lesser temperature but the modified MHNT's into the matrix steadily improved the thermal stability of the nanocomposites. This is due to the efficient interaction of the MHNT with epoxy and the epoxy makes the composites in a state of three dimensional cross linked network structures [26].

\subsection{Mechanical properties of hybrid nanocomposites}

Clay-PMMA-epoxy hybrid nanocomposites consist of modified clay nanoparticles and epoxy resin with low

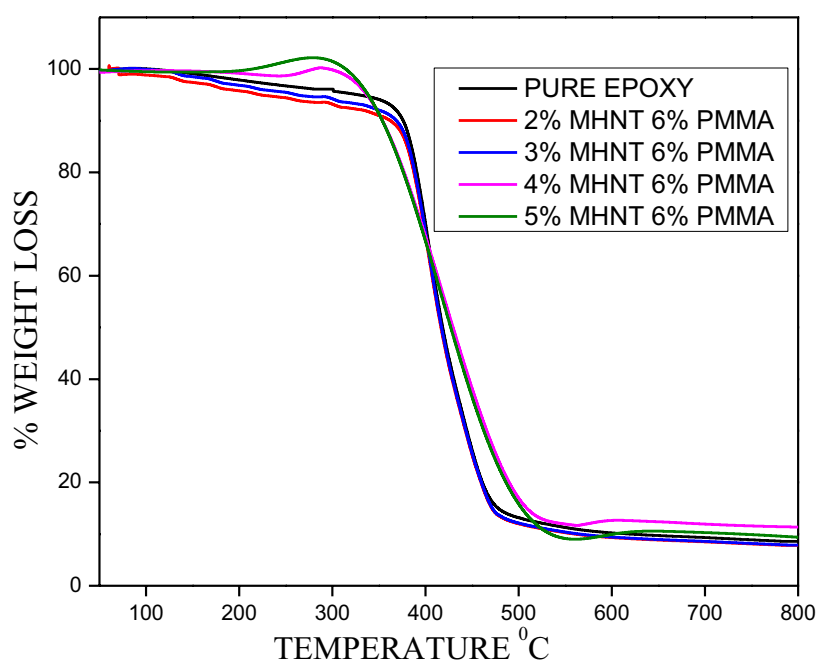

Fig. 7 TGA thermograms of neat epoxy and hybrid nanocomposites 


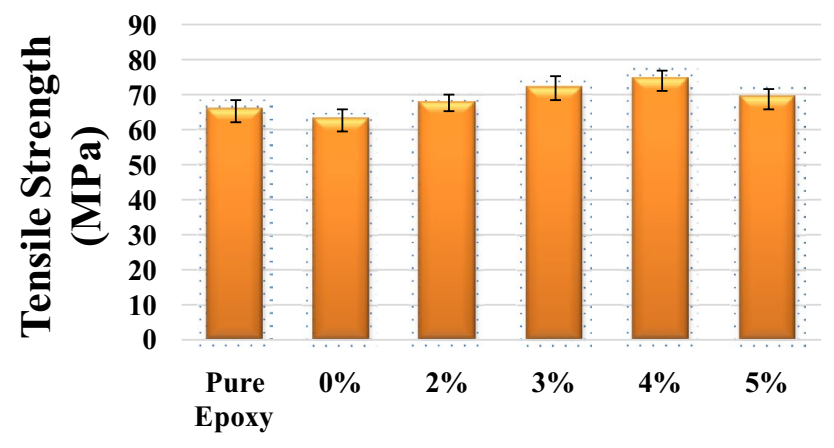

Loding of wt\% Clay and 6\% PMMA

Fig. 8 Tensile strength of neat epoxy and hybrid nanocomposites

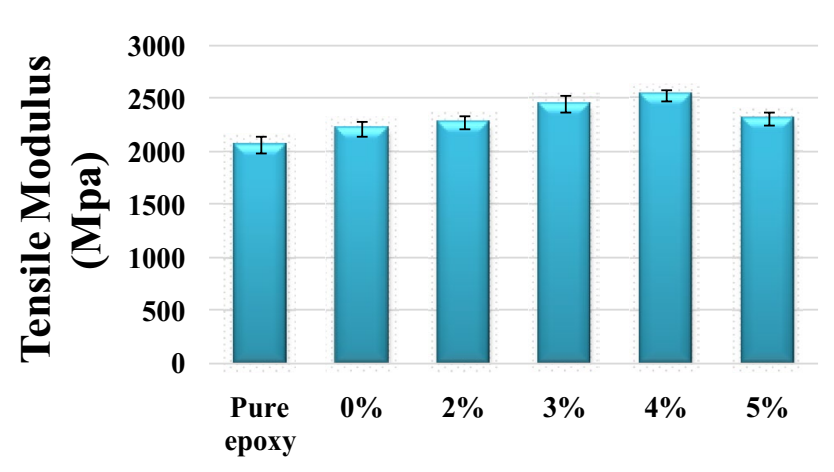

Loding of wt\% Clay and $6 \%$ PMMA

Fig. 9 Tensile Modulus of neat epoxy and hybrid nanocomposites

temperature solvent based PMMA solution were successfully fabricated through a simple sol-gel process and solvent evaporation. In order to evaluate the mechanical properties of hybrid nanocomposites we conducted tensile test, flexural stress, fracture toughness test and impact test according to ASTM standards. It was observed mechanical properties of hybrid nanocomposites increased with increase in MHNT's up to $4 \mathrm{wt} \%$ as shown in Figs. 8, 9, 10, 11 and 12. All the values indicate average value of five specimens in each composition.

Tensile strength of pure epoxy and epoxy/MHNT/ PMMA hybrid nanocomposites are presented in Fig. 8 with error bars corresponding to standard deviation. When PMMA polymer is added by $6 \mathrm{wt} \%$ into epoxy, tensile strength was decreased by $3.81 \%$. Now, by having the combination of epoxy, PMMA and HNT's we observed increase in tensile strength up to $4 \mathrm{wt} \%$ of MHNT's. The tensile strength is increased by $3.65 \%, 10 \%, 13.4 \%$ and $5.48 \%$ by adding $2,3,4$ and 5 wt $\%$ of MHNT's respectively and 6 wt $\%$ of PMMA into neat epoxy. Indeed, for hybrid nanocomposites introducing PMMA and MHNT's, the strength increased in response of MHNT concentration.

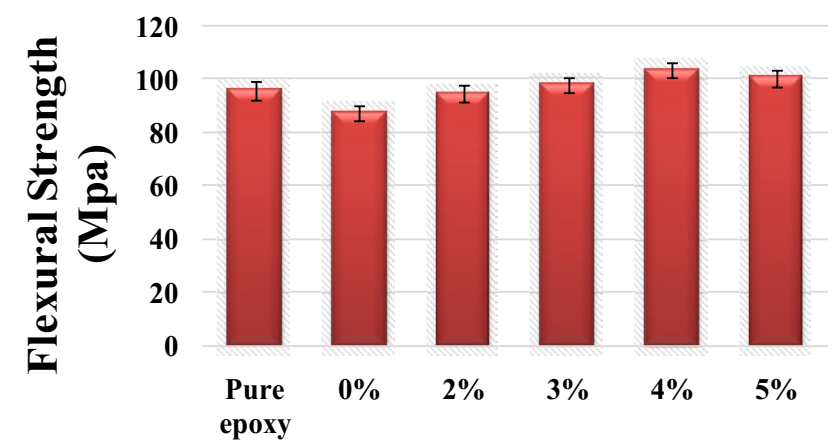

Loding of wt\% Clay and $6 \%$ PMMA

Fig. 10 Flexural strength of neat epoxy and hybrid nanocomposites

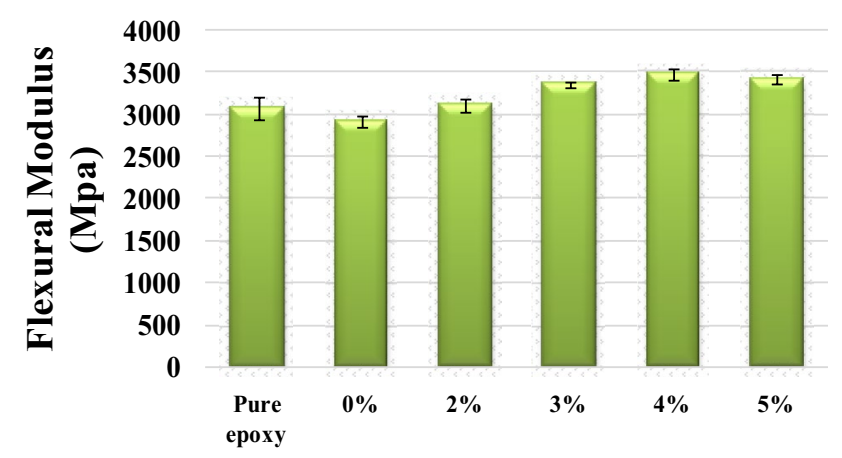

Loding of wt\% Clay and $6 \%$ PMMA

Fig. 11 Flexural Modulus of neat epoxy and hybrid nanocomposites

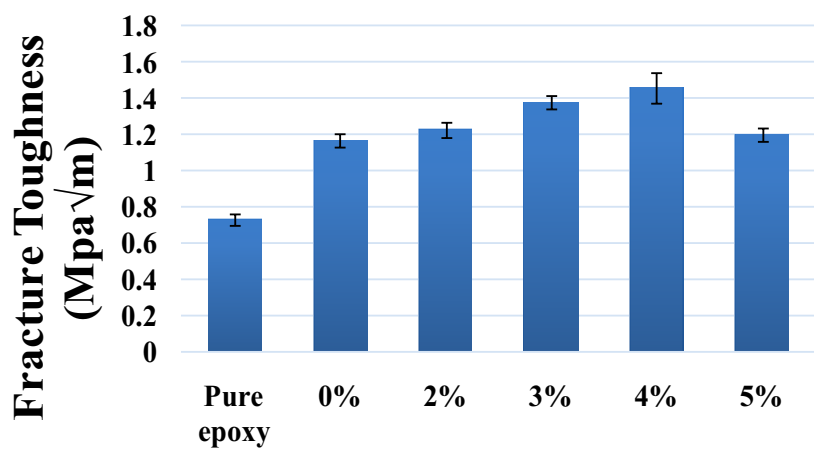

Loding of wt\% Clay and 6\% PMMA

Fig. 12 Fracture toughness of neat epoxy and hybrid nanocomposites

It can be observed that the young's modulus of hybrid nanocomposites is increased by $10.14 \%, 18.8 \%, 22.7 \%$ and $12.07 \%$ by adding $2,3,4$ and $5 \mathrm{wt} \%$ of MHNT's respectively and 6 wt $\%$ of PMMA into neat epoxy. Therefore for hybrid nanocomposites, tensile strength enhancement is directly proportional to amount of MHNT's and the effect of PMMA 
has only influence on tensile modulus. Higher interfacial properties of MHNT also have contributed to enhancement of tensile modulus [27].

Improvement of tensile modulus and strength and preservation of ductility indicate that the strengthening effect of the MHNT's and the ductility improvement of PMMA are concurrently functioning in the hybrid nanocomposites.

Flexural strength is another significant directory to assess the mechanical properties of hybrid epoxy nanocomposites. The flexural strength at fracture measured under three-point bending of epoxy monomer modified with MHNT's and PMMA is shown in Fig. 10. Flexural strength increases with increasing the MHNT's loading, reducing of the increasing trend after $4 \mathrm{wt} \%$ of MHNT's. The flexural strengths of hybrid nanocomposites with $6 \%$ PMMA and 4\% MHNT's are higher by $8 \%$ compared to neat epoxy. Similarly, as shown in Fig. 11 the flexural modulus increases by $1.3 \%, 9 \%, 13 \%$ and $11 \%$ for $2,3,4$ and 5 wt $\%$ of MHNT's and 6 wt\% of PMMA in epoxy system. Flexible chains in the PMMA structure would diminish the rigidity of the epoxy chain and consequence in the decline of the flexural strength. Alternatively, plenty amount of active hydroxyl groups in PMMA would contribute to improve the cross-connecting density and then advance the mechanical properties [28]. On the whole, the MHNT's together with PMMA can improve the flexural strength and flexural modulus of hybrid nanocomposites.

Fracture toughness of the hybrid nanocomposites in terms of the critical stress intensity factor was measured at normal temperature. Figure 12 displays fracture toughness of SENB specimens of neat epoxy and MHNT's/PMMA/ Epoxy hybrid nanocomposites. The values of neat epoxy fracture toughness and impact strength were calculated to be $0.73 \mathrm{MPa} \sqrt{\mathrm{m}}$ and $18 \mathrm{~kJ} / \mathrm{m}^{2}$ respectively, which are usual for an unmodified, highly cross-connected brittle epoxy. As depicted in Fig. 12, neat epoxy shows less fracture toughness value, due to unstable brittle crack growth behavior where the crack propagates by the characteristic slip mechanism. Inclusion of PMMA in epoxy matrix greatly improved fracture toughness and impact strength relative to the neat epoxy, as has been clarified previously. The sample which consists of 4 wt\% of HNT's and 6 wt $\%$ of PMMA has highest value which indicates a stable crack growth characteristic. Increases of approximately $95 \%$ were observed in fracture toughness by adding of $4 \mathrm{wt} \%$ of HNT's and 6 wt $\%$ of PMMA. It can be observed that after $4 \mathrm{wt} \%$ of modified HNT, composites exhibit lower fracture toughness and sudden failure. This sudden failure mechanism occurs since higher HNT wt\% leads to brittle the composites. Hybrid nanocomposites fracture behavior is dependent on the HNT's and PMMA compositions.

It is understood that during the fracture process, the stress field ahead of the crack tip caused the PMMA core to cavitate. Proof of cavitation will be shown in SEM analysis. These cavitated particles begin and assist subsequent matrix shear yielding [29].

In hybrid nanocomposites, on the other hand, adding of MHNT's and PMMA did not influence any substantial change to epoxy impact strength. Although the MHNT content was raised from 1 to $5 \mathrm{wt} \%$ the impact strength remained almost constant relative to the neat epoxy. Kinloch and Taylor [30] studied the mechanical and fracture properties of Nanomer modified epoxy specimens. Analogous to present findings, these researchers also observed only a little effect of nanoclay in impact strength of epoxy.

\section{Conclusion}

Epoxy/PMMA/HNT hybrid nanocomposites were prepared by adding 2, 3, 4, and $5 \mathrm{wt} \%$ of HNT's and $6 \mathrm{wt} \%$ of PMMA into neat epoxy. Effects of HNT's and PMMA on mechanical and thermal properties of hybrid nanocomposites were investigated.

The tensile strength is increased by $3.65 \%, 10 \%, 13.4 \%$ and $5.48 \%$ by adding $2,3,4$ and 5 wt $\%$ of MHNT's respectively and $6 \mathrm{wt} \%$ of PMMA into neat epoxy. The young's modulus of hybrid composite is increased by $10.14 \%$, $18.8 \%, 22.7 \%$ and $12.07 \%$ by adding $2,3,4$ and $5 \mathrm{wt} \%$ of HNT's respectively and $6 \mathrm{wt} \%$ of PMMA into neat epoxy. The flexural strengths of hybrid nanocomposites with $6 \%$ PMMA and 4\% HNT's are higher by $8 \%$ compared to neat epoxy. The flexural modulus increases by $1.3 \%, 9,13 \%$ and $11 \%$ for $2,3,4$ and 5 wt $\%$ of HNT's and 6 wt $\%$ of PMMA in epoxy system. The sample which consists of $4 \mathrm{wt} \%$ of HNT's and 6 wt $\%$ of PMMA has highest value of fracture toughness which indicates a stable crack growth characteristic. Increases of approximately $95 \%$ were observed in fracture toughness by adding of 4 wt $\%$ of HNT's and 6 wt $\%$ of PMMA. Higher thermal stability of hybrid nanocomposites is noticed at more than $4 \mathrm{wt} \%$ of clay is added with the combination of $6 \mathrm{wt} \%$ PMMA.

\section{Compliance with ethical standards}

Conflict of interest The authors declare that they have no known competing financial interests or personal relationships that could have appeared to influence the work reported in this paper.

\section{Refrences}

1. Kishi H, Kunimitsul Y, Nakashima Y, Imade J, Oshita S, Morishita Y, Asada M (2017) Relationship between the mechanical properties of epoxy/PMMA-b-PnBA-b-PMMA copolymer blends and 
their three-dimensional nanostructures. eXPRESS Polym Lett 11:765-777

2. Bashar M, Sundararaj U, Mertiny P (2012) Microstructure and mechanical properties of epoxy hybrid nanocomposites modified with acrylic tri-block-copolymer and layered-silicate nanoclay. Compos Part A 43(6):945-954

3. Bakar M, Skrzypek K (2007) Effect of kaolin and polyurethane on the fracture and thermal properties of epoxy based compositions. Mater Sci (Medžiagotyra) 13:324-329

4. Li Shuiping, Cui Chong, Hou Haijun, Qisheng Wu, Zhang Shuang (2015) The effect of hyperbranched polyester and zirconium slag nanoparticles on the impact resistance of epoxy resin thermosets. Compos B 79:342-350

5. Rostamiyan Y, Fereidoon A, Ghalebahman AG, Mashhadzadeh AH, Salmankhani A (2015) Experimental study and optimization of damping properties of epoxy-based nanocomposite: effect of using nanosilica and high-impact polystyrene by mixture design approach. Mater Des 65:1236-1244

6. Carolan D, Ivankovic A, Kinloch AJ, Sprenger S, Taylor AC (2016) Toughening of epoxy-based hybrid nanocomposites. Polymer 97:179-190

7. Zhang $\mathrm{H}$ et al (2006) Property improvements of in situ epoxy nanocomposites with reduced inter-particle distance at high nano silica content. Acta Mater 54:1833-1842

8. Bakar M, Białkowska A, Rudecka J, Bachan D (2012) Preparation and properties evaluation of an epoxy resin toughened by a combination of reactive polyester and kaolin. Polym Polym Compos 20:218-228

9. Pathak AK, Borah M, Gupta A, Yokozeki T, Dhakate SR (2016) Improved mechanical properties of carbon fiber/graphene oxide-epoxy hybrid composites. Compos Sci Technol 135:28-38

10. Mounif E, Liang GG, Cook WD, Bellenger V, Tcharkhatchi A (2009) Poly(methyl methacrylate)- modified epoxy/amine system for reactive rotational moulding: crosslinking kinetics and rheological properties. Polym Int 58:954-962

11. Lvov Yuri, Wang Wencai, Zhang Liqun, Fakhrullin Rawil (2016) Halloysite clay nanotubes for loading and sustained release of functional compounds. Adv Mater 28:1227-1250

12. Liu M, Jia Z, Jia D, Zhou C (2014) Recent advance in research on halloysite nanotubes-polymer nanocomposites. Prog Polym Sci 39:1498-1525

13. Rudresh M, Maruthi BH (2018) Effect of PMMA on microstructure and mechanical properties of epoxy polymer blends. Int J Res Advent Technol 6:1954-1959

14. Rudresh M, Maruthi BH, Nagaswarupa HP (2019) Mechanical assisted modification of halloysite nano clay: characterization and its effects on mechanical properties of halloysite-epoxy nanocomposites. Asian J Eng Appl Technol 8:32-37

15. Kaya GG, Yilmaz E, Deveci H (2018) Sustainable bean pod/calcined kaolin reinforced epoxy hybrid composites with enhanced mechanical, water sorption and corrosion resistance properties. Constr Build Mater 162:272-279

16. Li M, Wen X, Liu J, Tang T (2014) Synergetic effect of epoxy resin and maleic anhydride grafted polypropylene on improving mechanical properties of polypropylene/short carbon fiber composites. Compos Part A 67:212-220
17. Bakar M, Białkowska A, Molenda J, Piasek J (2012) Preparation and properties evaluation of thermoplastic modified epoxy nanocomposites. J Macromol Sci R Part B: Phys 51:1159-1171

18. Liu Mingxian, Guo Baochun, Mingliang Du, Cai Xiaojia, Jia Demin (2007) Properties of halloysite nanotube-epoxy resin hybrids and the interfacial reactions in the systems. Nanotechnology 18:45-50

19. Yue Baohua, Wang Yubing, Huang Chien-Yueh, Pfeffer Robert, Iqbal Zafar (2007) Polymeric nanocomposites of functionalized carbon nanotubes synthesized in supercritical $\mathrm{CO}_{2}$. J Nanosci Nanotechnol 7:994-1000

20. Rostamiyan Y, Mashhadzadeh AH, Khani AS (2014) Optimization of mechanical properties of epoxy-based hybrid nanocomposite: effect of using nano silica and high-impact polystyrene by mixture design approach. Mater Des 56:1068-1077

21. Zabihi O, Ahmadi M, Nikafshar S, Preyeswary KC, Naebe M (2017) A technical review on epoxy-clay nanocomposites: structure, properties, and their applications in fiber reinforced composites. Compos Part B 8:238-248

22. Isik Isil, Yilmazer Ulku, Bayram Goknur (2003) Impact modified epoxy/montmorillonite nanocomposites: synthesis and characterization. Polymer 44:6371-6377

23. Shiravand Fatemeh, Hutchinson John M, Calventus Yolanda, Ferrando Francesc (2014) Comparison of the nanostructure and mechanical performance of highly exfoliated epoxy-clay nanocomposites prepared by three different protocols. Materials 7:4196-4223

24. Bae Young-Han et al (2018) Synergistic effects of segregated network by PMMA beads and sintering of copper nanoparticles on thermal and electrical properties of epoxy composites. Compos Sci Technol 155:144-150

25. Liu Mingxian, Guo Baochun, Du Mingliang, Lei Yanda, Jia Demin (2008) Natural inorganic nanotubes reinforced epoxy resin nanocomposites. J Polym Res 15:205-212

26. Kanimozhi K, Sethuraman K, Selvaraj V, Alagar M (2014) Development of rice husk ash reinforced bismaleimide toughened epoxy nanocomposites. Front Chem 2:1-9

27. Bashar M, Sundararaj U, Mertiny P (2012) Microstructure and mechanical properties of epoxy hybrid nanocomposites modified with acrylic tri-block-copolymer and layered-silicate nanoclay. Compos Part A 43:945-954

28. Zhang D, Jia D (2006) Synthesis of novel low-viscosity liquid epoxidized aromatic hyperbranched polymers. Eur Polym J 42:711-714

29. Liu J, Sue H-J, Thompson ZJ, Bates FS, Dettloff M, Jacob G (2008) Nanocavitation in self-assembled amphiphilic block copolymermodified epoxy. Macromolecules 41:7616-7624

30. Kinloch J, Taylor AC (2003) Mechanical and fracture properties of epoxy/inorganic micro and nano-composites. J Mater Sci Lett 22:1439-1441

Publisher's Note Springer Nature remains neutral with regard to jurisdictional claims in published maps and institutional affiliations. 